\title{
Erratum to: Extracellular protein production and morphogenesis of Lentinula edodes in submerged culture
}

\author{
Olga M. Tsivileva • Alexei N. Pankratov •
}

Valentina E. Nikitina

Published online: 23 October 2009

(C) German Mycological Society and Springer 2009

Erratum to: Mycol Progress (2009)

DOI 10.1007/s11557-009-0614-4

In the original published version of this article the category was not given correct. The category should read Review (not Original Article).

The online version of the original article can be found at http://dx.doi. org/10.1007/s11557-009-0614-4.

O. M. Tsivileva $(\bowtie) \cdot$ V. E. Nikitina Laboratory of Microbiology, Institute of Biochemistry and

Physiology of Plants and Microorganisms of the Russian

Academy of Sciences,

13 Entuziastov Avenue,

Saratov 410049, Russia

e-mail: tsivileva@ibppm.sgu.ru
A. N. Pankratov
Institute of Chemistry,
N. G. Chernyshevskii Saratov State University,
83 Astrakhanskaya Street,
Saratov 410012, Russia 